\title{
Coronary stent mimicking as foreign body in the left bronchus in an elderly woman with acute onset of cough: a confusing artefact
}

\author{
Iranna Hirapur, ${ }^{1}$ Rajeshwari Veeranna Mantgol, ${ }^{2}$ Navin Agrawal, $^{3}$ \\ Anand Kumar Dasappa ${ }^{1}$
}

'Department of Cardiology, R L Jalappa Narayana Hrudayalaya Heart Center, Kolar, Karnataka, India ${ }^{2}$ Department of Opthalmology, R L Jalappa Narayana Hrudayalaya Heart Center, Kolar, Karnataka, India ${ }^{3}$ Department of Cardiology, Care Hospital, Surat, Gujarat, India

Correspondence to Dr Navin Agrawal, drnavinagrawal@gmail.com
CrossMark

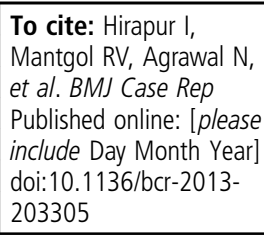

\section{DESCRIPTION}

Coronary stents can sometimes produce a confusing picture on routine $\mathrm{X}$-rays which can mimic a foreign body if the clinician is not suspicious of this artefact which may lead to inappropriate treatment in an appropriate case scenario. We present an interesting case of an 85-year-old woman who presented with an acute anterior wall myocardial infarction. She underwent angioplasty with stent to left anterior descending (LAD) for a proximal LAD lesion (figure $1 \mathrm{~A}, \mathrm{~B}$, videos 1-2). The patient had been implanted with a $3 \times 18 \mathrm{~mm}$ Sirolimus eluting stainless steel EXCEL stent. The stents made of stainless steel can be better seen on the X-ray or fluoroscopy than the stents made of cobaltchromium. The main reason for this is the strut thickness of the cobalt-chromium stents is smaller than the strut thickness of the stainless steel stents. ${ }^{12}$ The patient was subsequently discharged after 3 days.

One month later she presented to a local physician with dry cough which had abruptly worsened. Based on chest X-ray a foreign body in the left bronchus was suspected and the patient was referred to a pulmonologist and a bronchoscopist for extraction of the 'foreign body'. The patient was evaluated by the pulmonologist and a bronchoscopic evaluation was planned but the repeat X-ray and the clinical scenario seemed inappropriate for the diagnosis and the patient was referred back to us for fluoroscopic evaluation and further management. As soon as fluoroscopy was performed we immediately realised that it was actually the stent which was apparent on the routine X-ray as a
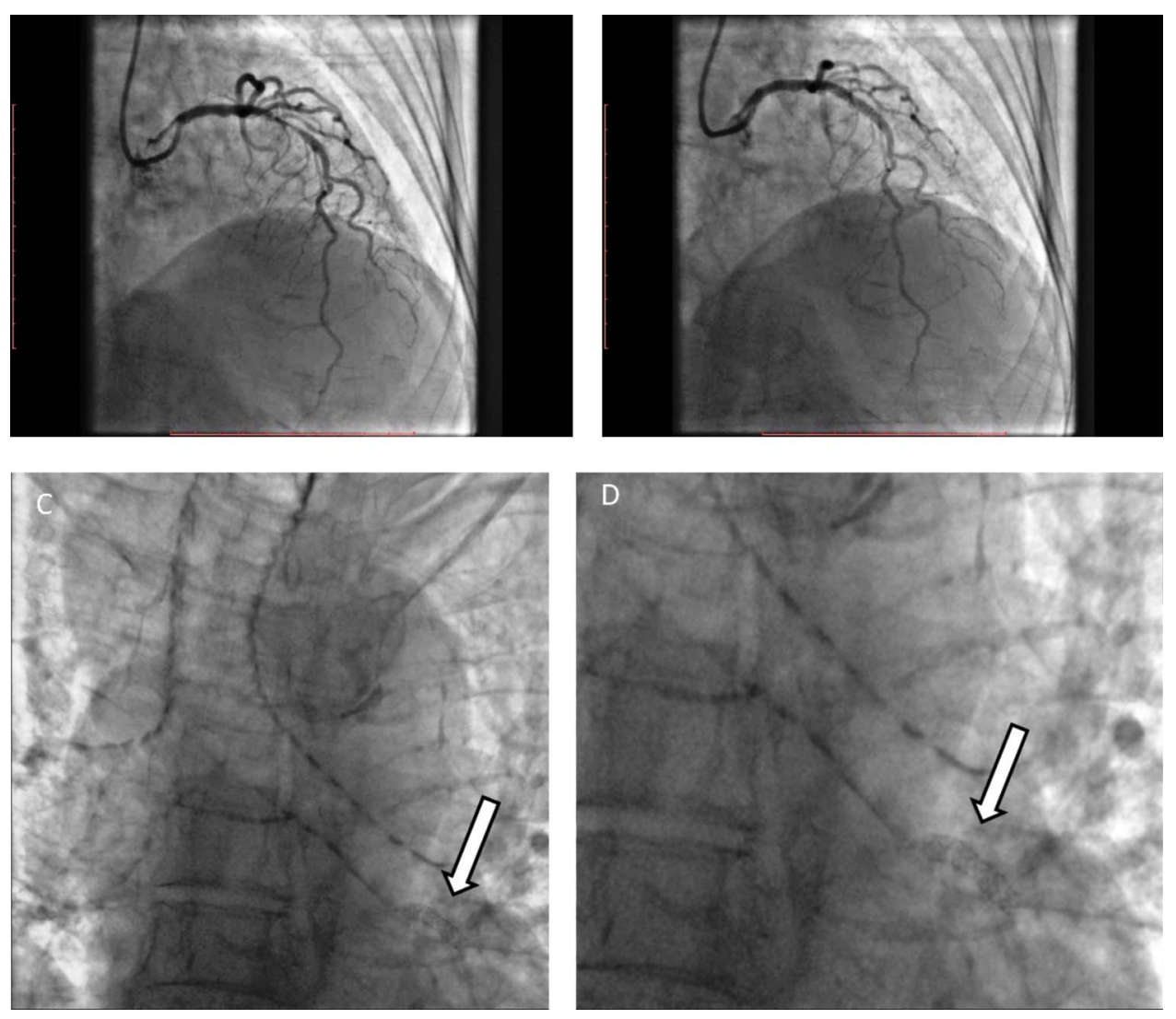

Figure 1 (A) The angiographic image prior to angioplasty showing a tight lesion in the left anterior descending artery. (B) The angiographic image after the procedure showing the successfully treated lesion with good postprocedure result. ( $C$ and D) The fluoroscopic image of the patient showing the stent image overlapping the left bronchus which appeared as a foreign body on the routine X-ray. 


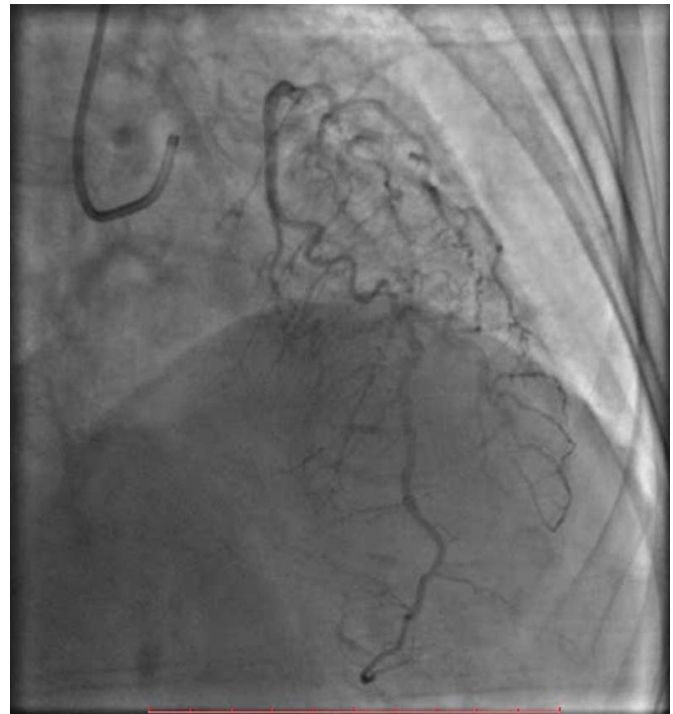

Video 1 The angiographic image prior to angioplasty showing a tight lesion in the left anterior descending artery.

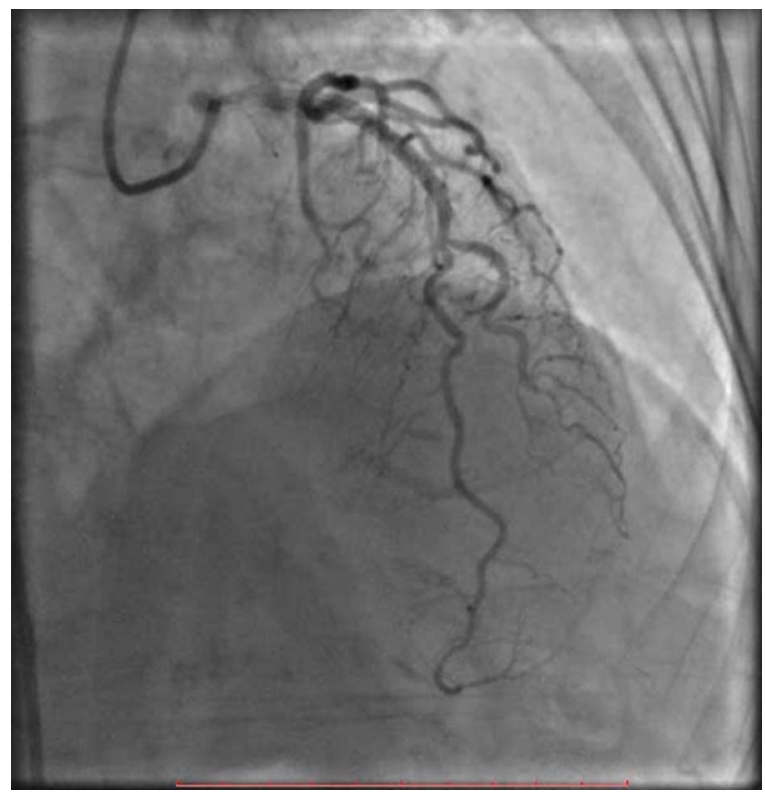

Video 2 The angiographic image after the procedure shows the successfully treated lesion with good post procedure result. foreign body because of the overlap on the two structures and the only treatment which the patient required was to replace the ACE inhibitors (figure 1C,D).

This case illustrates the importance of this high index of suspicion for this confusing artefact and good clinical judgement and appropriate investigations in dealing with such cases. ${ }^{3-5}$

\section{Learning points}

- Stents can present as a confusing artefact on the X-ray and can mimic a foreign body if the index of suspicion is not high and should be kept high on the list of differentials in such X-rays.

- In case of such confusion a fluoroscopic evaluation or a lateral X-ray and an appropriate clinical history and evaluation can be of great help and can avoid unnecessary investigations and treatments as in our case.

- ACE inhibitor induced dry cough should always be kept high on the list of differentials in any patient who presents with abrupt onset of dry cough without any other obvious explanation especially if the patient does not have symptoms of heart failure and orthopnoea although lung malignancy should be ruled out in case of an elderly patient as in our case.

Contributors All the authors have contributed to the drafting and finalising of the manuscript and have helped in patient care.

Competing interests None.

Patient consent Obtained.

Provenance and peer review Not commissioned; externally peer reviewed.

\section{REFERENCES}

1 Stoeckel D, Bonsignore C, Duda S. A survey of stent designs. Minim Invasive Ther Allied Technol 2002;11:137-47.

2 Medtronic: Advantages of Cobalt Alloy for Coronary Stents. Global Healthcare: Advanced Medical Technologies, 2004, http://wwwp.medtronic.com/newsroom/ Content/1110132739468.pdf, 20/02/2006.

3 Brooks JW. Foreign bodies in the air and food passages. Ann Surg 1972;175:720-32.

4 David SS, Subbiah B. Foreign bodies in the air and food passages in children. Indian Paediatr 1972;10:183-5.

5 Gupta A, Chopra K, Saha M, et al. Foreign bodies in the tracheobronchial tree. Indian Paediatr 1977;14:133-4.

Copyright 2014 BMJ Publishing Group. All rights reserved. For permission to reuse any of this content visit http://group.bmi.com/group/rights-licensing/permissions.

BMJ Case Report Fellows may re-use this article for personal use and teaching without any further permission.

Become a Fellow of BMJ Case Reports today and you can:

- Submit as many cases as you like

- Enjoy fast sympathetic peer review and rapid publication of accepted articles

- Access all the published articles

- Re-use any of the published material for personal use and teaching without further permission

For information on Institutional Fellowships contact consortiasales@bmjgroup.com

Visit casereports.bmj.com for more articles like this and to become a Fellow 